\title{
PENGARUH PELATIHAN, MOTIVASI, DAN KEPUASAN KARYAWAN TERHADAP KINERJA KARYAWAN DI UD. RAHMAN (SIDOTOPO WETAN, SURABAYA)
}

\author{
Raynaldy Rizky Rahmawan, Mei Retno Adiwati \\ Program Studi Manajemen, Fakultas Ekonomi dan Bisnis, \\ Universitas Pembangunan Nasional "Veteran" Jawa Timur \\ E-mail: raynaldyrizkyr26@gmail.com
}

\begin{abstract}
This research aims to find out the Effect of Training, Motivation, And Employee Satisfaction on Employee Performance. This study used questionnaires that used scoring techniques on likert scale techniques. The sample in this study is that all members of the population are sampled, namely Workers who work in UD. RAHMAN numbered 32 people. Analytical Techniques and Hypothesis Testing Techniques Analysis using PLS (Partial Least Square). The results of this study showed that training does not have a significant influence on employee performance, motivation has a significant effect on employee performance, satisfaction does not have a significant influence on employee performance.
\end{abstract}

Keywords : Effect of Training, Motivation, Employee Satisfaction, Employee Performance

\section{PENDAHULUAN}

Dinamika tuntutan zaman membuat suatu usaha harus di siapkan dengan begitu sangat matang, begitu juga dengan dunia ketenagakerjaan. suatu perusahaaan pasti menginginkan suatu hal yang baik dalam lingkungan perusahan nya itu sendiri, baik itu dari sisi input karyawan nya maupun dari sisi ouput prodak yang di hasilkan.

Perusahaan kerap kali menekankan suatu prosedur yang mereka telah tetapkan, baik itu dari system perekrutan karyawan, proses penempatan karyawana, dan juga kompensasi. sehingga dari segala upanya yang telah di lakukan oleh perusahaan sendiri diharapkan dapat menghasilkan output prodak yang baik, Baik itu dari jasa atau dari suatu prodak lain yang di hasilkan oleh perusahaan itu sendiri.

Era keterbukaan sekarang ini yang semakin terbuka dan sulit dalam persaingan kerja serta pemanfaatan teknologi yang semakin beragam. Oleh karena itu karyawan merupakan aset dan ujung tombak dari suatu perusahan, dengan itu untuk mendapatkan karyawan yang handal, cekatan serta memilikikompetensi yang di butuhkan oleh perusahaan maka dari itu perusahaan di wajibkan untuk memberikan suatu dorongan motivasi baik itu rewed, tunjangan, upah, kompensasi atau dalam bentuk lainnya.

Pemberian pelatihan yang cukup efektif di harapkan dapat meningkatkan tingkat kepuasan oleh karyawan sehingga para karyawan otomatis akan semakin terpacu, termotifasi, dan sebagai bentuk dorongan guna untuk meningkatkan produktifitas dan kinerja karyawan dari yang sebelumnyabelum tercapai. 
Hal ini juga juga telah di terapkan oleh UD. Rahman yang bergerak bidang produksi sepatu dan sandal. UD. Rahman telah memberikan pelatihan yang cukup efektif. Namun kemungkinan para karyawan kurang merasa puas dan merasa termotivasi dengan adanya pelatihan yang di berikan oleh UD. Rahman kepada para karyawannya sehingga kinerja para karyawan terhadapperusahaan berkurang. Hal ini di buktikan dengan presentasi data produksi dan realita produksi, Adapun realisasi produksi dan target produksi UD. RAHMAN tersebut antara lain adalah sebagai berikut :

Tabel 1. Data Produktifitas UD.RAHMAN

\begin{tabular}{|c|c|c|c|c|c|c|c|c|}
\hline \multirow{2}{*}{ Tahun } & \multicolumn{4}{|c|}{ target produksi (perpasang) } & \multicolumn{4}{c|}{ Prodak yang terealisasi } \\
\cline { 2 - 9 } & $\begin{array}{c}\text { sendal } \\
\text { anak }\end{array}$ & $\begin{array}{c}\text { Sendal } \\
\text { dewasa }\end{array}$ & $\begin{array}{c}\text { Sepatu } \\
\text { anak }\end{array}$ & $\begin{array}{c}\text { Sepatu } \\
\text { dewasa }\end{array}$ & $\begin{array}{c}\text { sendal } \\
\text { anak }\end{array}$ & $\begin{array}{c}\text { Sendal } \\
\text { dewasa }\end{array}$ & $\begin{array}{c}\text { Sepatu } \\
\text { anak }\end{array}$ & $\begin{array}{c}\text { Sepatu } \\
\text { dewasa }\end{array}$ \\
\hline 2017 & 2400 & 4200 & 2040 & 1560 & 2356 & 3348 & 2080 & 1645 \\
\hline Persen & $24 \%$ & $41 \%$ & $20 \%$ & $15 \%$ & $24 \%$ & $35 \%$ & $22 \%$ & $17 \%$ \\
\hline 2018 & 3000 & 5400 & 2400 & 2400 & 2901 & 4553 & 2858 & 2566 \\
\hline Persen & $23 \%$ & $41 \%$ & $18 \%$ & $18 \%$ & $22 \%$ & $35 \%$ & $22 \%$ & $19 \%$ \\
\hline 2019 & 2400 & 4800 & 2400 & 2400 & 2498 & 4157 & 2583 & 2232 \\
\hline Pensen & $20 \%$ & $40 \%$ & $20 \%$ & $20 \%$ & $21 \%$ & $36 \%$ & $22 \%$ & $19 \%$ \\
\hline
\end{tabular}

Sumber UD. RAHMAN

Dari data presentasi produksi UD. Rahman dapat di lihat bahwasannya UD. Rahman memproduksi sendal anak mau pun sendal dewasa, serta sepatu anak sampai dengan sepatu dewasa. Dengan realisasi produksi 2017 yaitu sendal anak 2356 dari tardet produksi sebesar 2400, sendal dewasa 3348 dari terget produksi sebesar 4200, untuk sepatu anak dapat memenuhi produksi yaitu sebesar 2080 dari target produksi yaitu 2040, begitu juga sepatu anak dapat memenuhi produksisebesar 1645 dari target produksi sebesar 1560.

Sementara pada tahun 2018 dengan nilai produksi sebesar 2901 dengan target produksi 3000 untuk sendal anak, 4553 untuk sendal dewasa dengan target produksi sebesar 5400, untuk sepatu anak memenuhi produksi sebesar 2858 dari target produksi sebesar 2400, begitu juga dengan sepatu dewasa dapat memenuhi produksisebesar 2566 dari target produksi sebesar 2400 .

Adapun ditahun 2019 untuk sendal anak mengalami kenaikan produksi sebesar 2498 dari target produsi yaitu 2400, sementara sendal dewasa tidak dapat memenuhi target produksi dan hanya dapat memproduksi sebesar 4157 dari target produksi sebesar 4800, kemudian dari sepatu anak dapat memenuhi produtivitas yaitu sesebesar 2583 dari target produksi yaitu sebesar 2400, disusul dengan produksi sepatu dewasa yaitu sebesar 2232 dari target produksi yaitu 2400.

Hal ini juga di pengaruhi oleh dengan tingkat absensi karyawan yang semakin tahun semakin naik, di buktikan dengan data table absensi 2017 sampai dengan 2019 adapun data tersebut yaitu antara lain sebagai berikut:

Tabel 2. Absensi Karyawan

\begin{tabular}{|c|c|c|c|c|c|c|}
\hline Tahun & $\begin{array}{c}\text { Jumlah } \\
\text { Karyawan }\end{array}$ & Izin & Sakit & $\begin{array}{c}\text { Tanpa } \\
\text { Keterangan }\end{array}$ & Total & Presentase \\
\hline 2017 & 32 & 36 & 26 & 19 & 81 & 0,35 \\
\hline 2018 & 32 & 34 & 44 & 19 & 97 & 0,42 \\
\hline 2019 & 32 & 34 & 103 & 33 & 170 & 0,75 \\
\hline
\end{tabular}

Sumber UD. RAHMAN 
Dari data yang di dapatkan tersebut di ketahui bahwa tingkat absensi kehadirankaryawan yang tidak masuk selama tiga tahun, di mulai pada tahun 2017 sampai dengan tahun 2019 mengalami prosentas peningkakatan yang cukup tinggi. Di lihat dari table yang ada di atas menunjukkan bahwa tingkat absensi karyawan pada tuhun 2017 sebesar 81 kali atau 0,35 persen yang tidak masuk pada 2017.

Kemudian pada tahun 2018 ada lonjakan lumayan sifnifikasikan yaitu sebesar 97 kali atau 0,42 persen dari persentasi kehadiran pada tahun 2018, hal ini semakindi perparah dengan, semakin meningkatnya Kembali tingkat abensi kehadiran karyawan pada tahun 2019 yaitu sebesar 170 kali atau 0,75 persen dengan persentasi kehadiran karyawan yang dari tahun ke tahun yang semakin meningkat, maka hal ini memepengaruh pada tingkat produksi dari UD. Raham itu sendiri.

Dari hasil penelitian menurut (Ningsi et al., 2016) , menyatakan pelatihan berpengaruh signifikan dan positif terhadap motivasi. sementara menurut (Marjaya \& Pasaribu, 2019) menerangkan bahwa motivasi yang berpengaruh positif namun tidak signifikan terhadap kinerja karyawan. Begitu juga penelitian yang di lakukan oleh (Sataloff et al., 2003) menyatakan bahwa kepuasan kerja tidak berpengaruh terhadap kinerja karyawan.

Dari data mini riset yang peneliti lakukan maka didapat hasil bahwa 78,10\% tidak pernah mengikuti pelatihan. hal ini juga memberikan efek yang kurang efektifdalam peningkatan kinerja. Dan dari rensonden yang berjumlah 32 orang itu di ketahui bahwa 50,40\% dari orang merasa tidak merasa termotivasi dalam melakukan pekerjaannya sehingga tingkat kepuasan serta kinerja para perkerja banyak yang mengalami penurunan hal ini kemungkinan disebabkan dengan kurangan bimbingan dan arahan dari atasan.

Dari perbedaan data - data tersebut guna menguji faktor-faktor dari tingkat pelatihan, motivasi dan kepusan kerja yang memengaruhi tingkat kinerja karyawan. Adapun penelitian ini terdiri dari varibel dependen dan independent. Maka dari itu, penulis merasa tertarik dan akan melakukan penelitian pengaruh pelatihan, motivasi, dan kepuasan karyawan terhadap kinerja karyawan.

\section{TINJAUAN PUSTAKA}

\section{Pengertian pelatihan}

Pada dasarnya setiap orang memiliki jiwa untuk terus berkembang dan memiliki rasa ingin tau yang besar serta ingin belajar serta mengexploitasi kemampuan yang di milikinya dengan maksimal, akan tetapi terkadang merekabelum menyadari tentang kemampuan yang ada pada diri mereka sendiri, khususnya bagi Sebagian karyawan.

Untuk mendukung kemampuan dan keahlian agar mereka semakin kompeten maka di butuh suatu pelatihan yang mempuni dan menunjang dari performa mereka sendiri, Adapun pengertian dari pelatihan yaitu Menurut (SIAGIAN, 2020) adalah proses pembelajaran dengan menggunakan berbagai cara untuk meningkatkan keterampilan dan kemampuan kerja seseorang atau sekelompok orang.

Pada dasarnya setiap orang ingin di motivasi baik dengan riwet, bonus atauyang lainnya di dalam satu sisi setiap orang ingin terus atau memiliki Hasrat untuk terus belajar dan mengembangkan diri mereka maka salah satu cara untuk memberikan motivasi kepada anggota perusahaan atau anggota organisasi yaitu di butuhkannya suatu Pemberian palatihan yang kompeten.

\section{Motivasi}


Motivasi karyawan adalah suatu hal yang sangat penting bagi perusahaan karena motifasi adalah suatu dorongan semangat bagi karyawan, kalau karyawan tersebut tidak di dorong dan di motivasi secara maksimal maka akan menggoyangkan kinerja perusaan dan bisa saja menghentikan aktivitas produksi bagi perusahaan kalau tidak di hendel dengan maksimal. Ada berbagi macam cara dalam memberikan suatu motivasi bagi suatu karyawan yaitu dengan pemberian riwet, tunjangan, jaminan kesekahatan, dan pelatihan.

\section{Kepuasan kerja}

Kepuasan kerja ialah sifat individual seseorang sehingga memiliki tingkat kepuasan yang berbeda sesuai dengan sistem nilai-nilai yang berlaku pada dirinya. Hal ini dikaitkan oleh adanya perbedaan emosional masing - masing individu. (Sunyoto, 2013).

\section{Kinerja karyawan}

Menurut (Poole, 2013) kinerja karyawan adalah tingkat pencapaian atau hasil kerja karyawan dari sasaran yang harus dicapai atau tugas yangharus dilaksanakan dalam kurun waktu tertentu. Sehingga dapat disimpulkan bahwa kinerja karyawan adalah kemampuan untuk mencapai syarat-syarat yang ada dalam pekerjaan, yang mana suatu target kerja harus dapat diselesaikan dengan tepat waktu sehingga visi dan misi dari suatu perusahaan dapat terwujud serta produktifitas perusahaan dapat.

\section{Kerangka Pikir}

\section{Pengaruh pelatihan terhadap kinerja karyawan}

Berdasarkan penelitian (Nugroho \& Paradifa, 2020). menyatakan bahwa pelatihan berpengaruh secara tidak langsung terhadap kinerja SDM melalui variabel intervening kompetensi. Hal ini berarti bahwa dengan pelatihan dapat mempengaruhi dan meningkatkan suatu kinerja karyawan agar lebih baik.

Dalam Penelitian ini variable pelatihan yang berpengaruh terhadap kinerja karyawan didukung dengan teori yaitu teori motivasi yang menjelaskanbahwa seseorang karyawan perlu didorong dengan motivasi agar dapat mengikuti pelatihan guna menumbuhkan dan memingkatkan kinerja didalamdirinya.

\section{Pengaruh motivasi terhadap kinerja karyawan}

(Susila et al., 2019) menyatakan bahwa motivasi kerja secara simultan dan parsial berpengaruh secara positif dan signifikan terhadap kinerja karyawan pada PT. Pegadaian (persero) Kantor Wilayah VManado. Hal ini menunjukkan dengan pemberian motivasi secara seksama dapat meningkatkan kinerja karyawan. penelitian itu di dasarkan dengan variable motivasi yang berpengaruh positif terhadap kinerja karyawan, dengan teori motivasi juga yang menjelaskan apabila motivasi ialah sebagai pendorong untuk menjadikan seseorang lebih bermutu agar bertujuan untukmeningkatakkan kineja karyawan.

\section{Pengaruh kepuasan terhadap kinerja}

(Setia et al., 2020) menyatakan bahwa kepuasan kerja memiliki pengaruh positif signifikan terhadap kinerja karyawan. Dalam hal ini berarti apabila jika kepuasan kerjasemakin meningkat maka kinerja karyawan semakin meningkat pula. Penilitian ini juga berdasarkan pada teori motivasi yaitu berupa Jika karyawan merasa puas dengan apa yang diperoleh dari perusahaan, maka karyawan akan memberikan hasil yang suatu semangat untuk 
memunuhi target perusahaan juga jika karyawan tidak puas maka tingkat target juga tidak akan tercapai.

\section{Kerangka konseptual}

Dari gambaran permasalahan yang ada maka kerangka konseptual dari penelitian ini adalah sebagai berikut

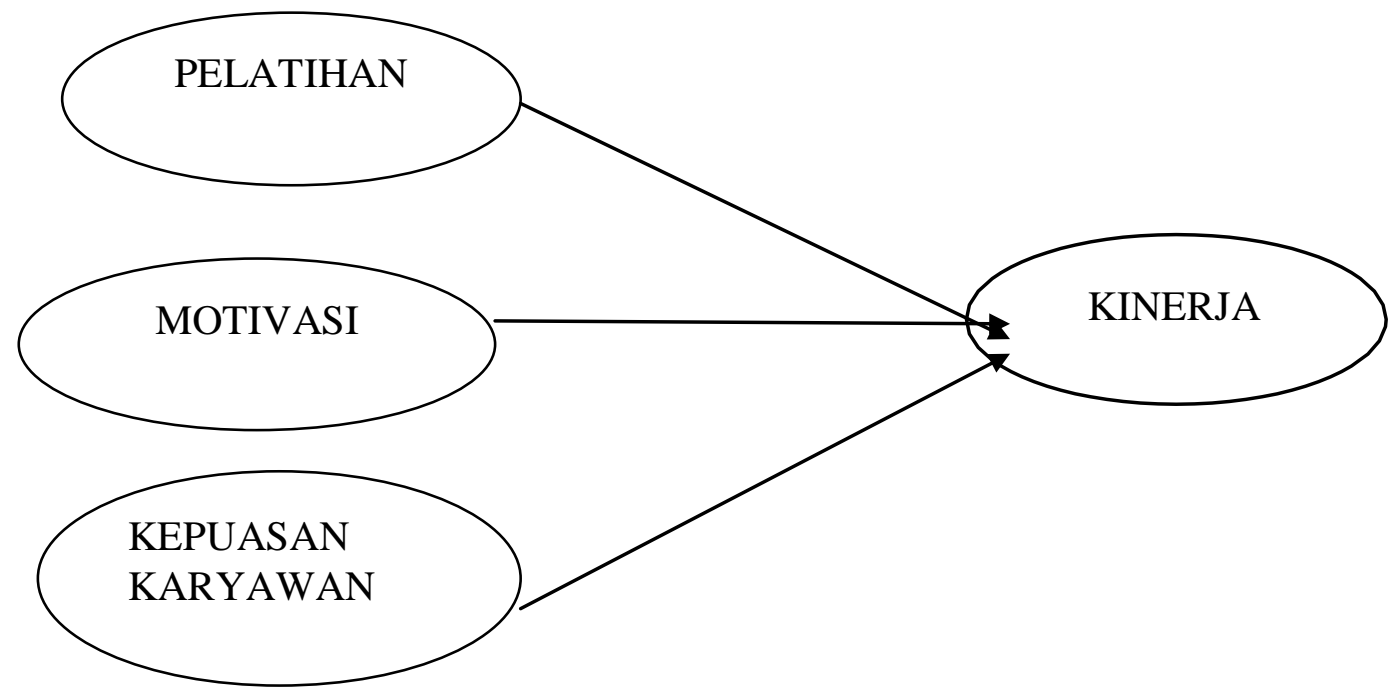

Gambar 1. Kerangka Konseptual

\section{Hipotesis}

Berdasarkan latar belakang masalah, perumusan masalah, landasan teori dan kerangka berpikir maka dapat disimpulkan bahwa:

$\mathrm{H} 1$ : di duga pelatihan berpengaruh positif terhadap kinerja karyawan

$\mathrm{H} 2$ : di duga motivasi berpengaruh positif terhadap kinerja karyawan

$\mathrm{H} 3$ : di duga kepuasan kerja berpengaruh positif terhadap kinerja karyawan

\section{METODE PENELITIAN}

Penelitian ini menggunakan kuesioner yang menggunakan teknik pemberian skor pada teknik skala likert (likert scale) yang biasanya dipakai buat mengukur sikap, pendapat, dan persepsi seseorang atau sekelompok orang tentang fenomena yang terjadi (Sugiyono., 2014). Dengan menggunakan teknik pembobotan skala likert, variabel yang diukur bisa dijabarkan menjadi indikator suatu variabel.

Populasi dalam penelitian ini adalah Buruh yang bekerja di UD RAHMAN berjumlah 32 orang, sampel dalam penelitian ini adalah seluruh anggota populasi dijadikan sampel yaitu Buruh yang bekerja di UD. RAHMAN berjumlah 32 orang.

Sumber data yang digunakan dalam penelitian ini adalah data yang diambil langsung dengan cara menyebarkan kuesioner dan wawancara kepada karyawan UD. RAHMAN. Teknik pengumpulan data yang dilakukan dengan cara memberikan seperangkat pertanyaan atau pernyataan kepada orang lain yang dijadikan responden untuk menjawab. Cara pengumpulan data dengan cara berkomunikasi bertatap muka atau bertemu langsunguntuk mendapatkan informasi yang dibutuhkan yang langsung dari sumbernya. Teknik Analisis dan Uji Hipotesis 
Teknik Analisis menggunakan PLS (Partial Least Square) Model analisis semua variabel laten dalam PLS sendiri menurut (Jogiyanto \& Abdillah, 2015), terdiri dari tiga set hubungan:

1) Inner model yang menspesifikasi hubungan antar variabel laten (structural model)

2) Outer model yang menspesifikasi hubungan antar variabel laten dengan indikator atau variabel manifestasinya (measurement model)

3) Dan yang ke 3 (tiga) Weight relation dimana nilai kasus dari variabel laten dapat diestimasi.

\section{HASIL DAN PEMBAHASAN}

\subsection{Hasil}

\subsubsection{Karakteristik Responden Berdasarkan Gender}

Tabel 3. persentasi gender

\begin{tabular}{|c|c|c|}
\hline laki - laki & 20 & $63 \%$ \\
\hline perempuan & 12 & $38 \%$ \\
\hline Jumlah & 32 & \\
\hline
\end{tabular}

Sumber UD.RAHMAN

Dapat diketahui bahwa dari 32 responden, dengan rincian karyawan sebanyak 20 orang $(63 \%)$ berjenis kelamin laki-laki dan rincian karyawan sebanyak 12 orang (38\%) berjenis kelamin perempuan. Berdasarkan pengolahan data tersebut, dapat disimpulkan bahwa sebagian besar $(63 \%)$ responden berjenis kelamin laki-laki

\subsubsection{Evaluasi Model Pengukuran (Outer Model)}

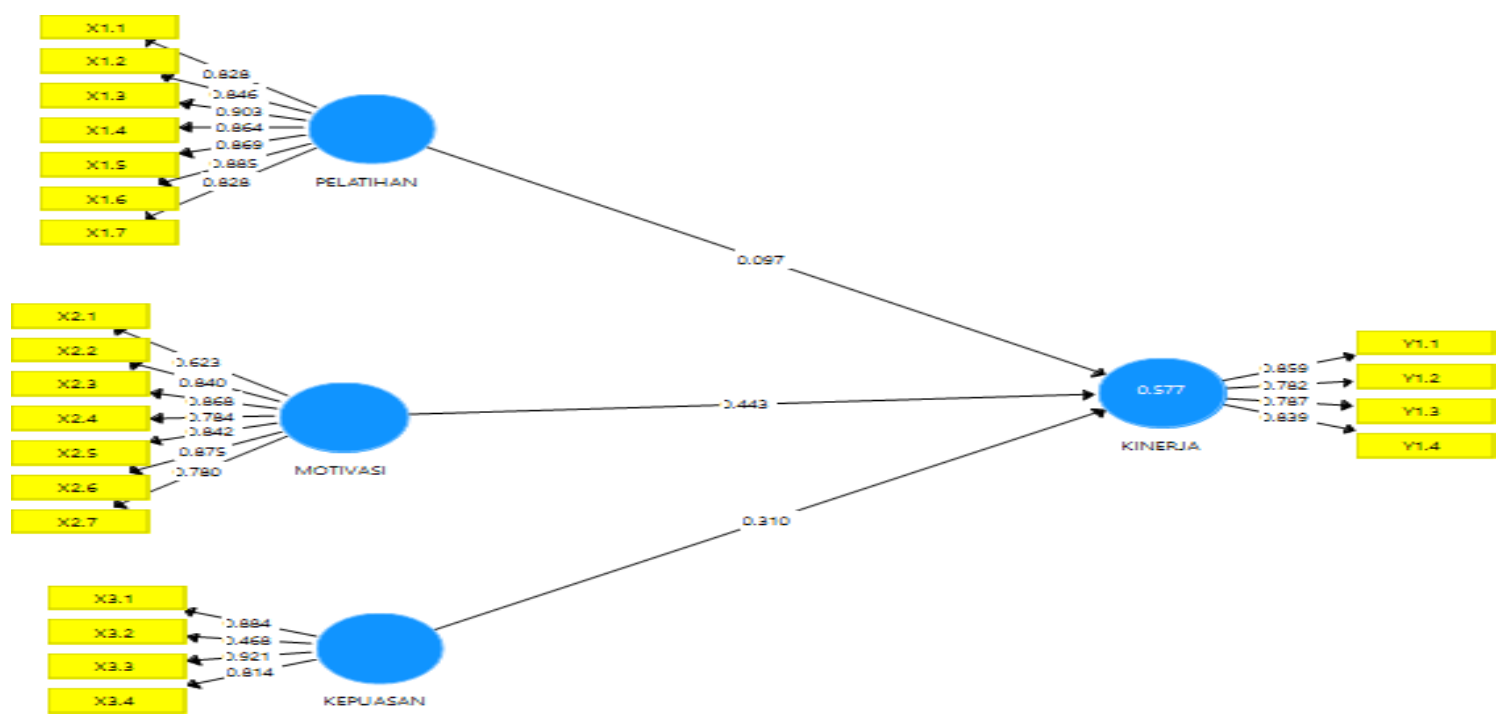

Gambar 2. Outer Loading Tahap pertama

Sumber: Data diolah, 2021

Tabel 4. Ouer Loading Tahap Pertama 


\begin{tabular}{|c|c|c|c|c|}
\hline & Kepuasan & Kinerja & Motivasi & Pelatihan \\
\hline X1.1 & & & & 0,828 \\
\hline X1.2 & & & & 0,846 \\
\hline X1.3 & & & & 0,903 \\
\hline X1.4 & & & & 0,864 \\
\hline X1.5 & & & & 0,865 \\
\hline X1.6 & & & & 0,885 \\
\hline X1.7 & & & & 0,828 \\
\hline X2.1 & & & 0,623 & \\
\hline X2.2 & & & 0,840 & \\
\hline X2.3 & & & 0,868 & \\
\hline X2.4 & & & 0,784 & \\
\hline X2.5 & & & 0,842 & \\
\hline X2.6 & & & 0,875 & \\
\hline X2.7 & & & 0,780 & \\
\hline X3.1 & 0,884 & & & \\
\hline X3.2 & 0,468 & & & \\
\hline X3.3 & 0,921 & & & \\
\hline X3.4 & 0,814 & & & \\
\hline Y1.1 & & 0,859 & & \\
\hline Y1.2 & & 0,782 & & \\
\hline Y1.3 & & 0,787 & & \\
\hline Y1.4 & & 0,839 & & \\
\hline
\end{tabular}

Berdasarkan pengelolaan data dengan menggunakan SmartPLS 3.0 pada loading factor tahap satu menunjukan dua indikator berwarna merah atau tidak valid. Indikator yang berwarna merah tersebut memiliki nilai dibawah 0,7. Hal ini menandakan indikator tersebut tidak memenuhi kriteria batas minimal pengukuran. Dengan demikian indikator tersebut dihapus dan kemudian dilakukan pengelolahan data ditahap kedua

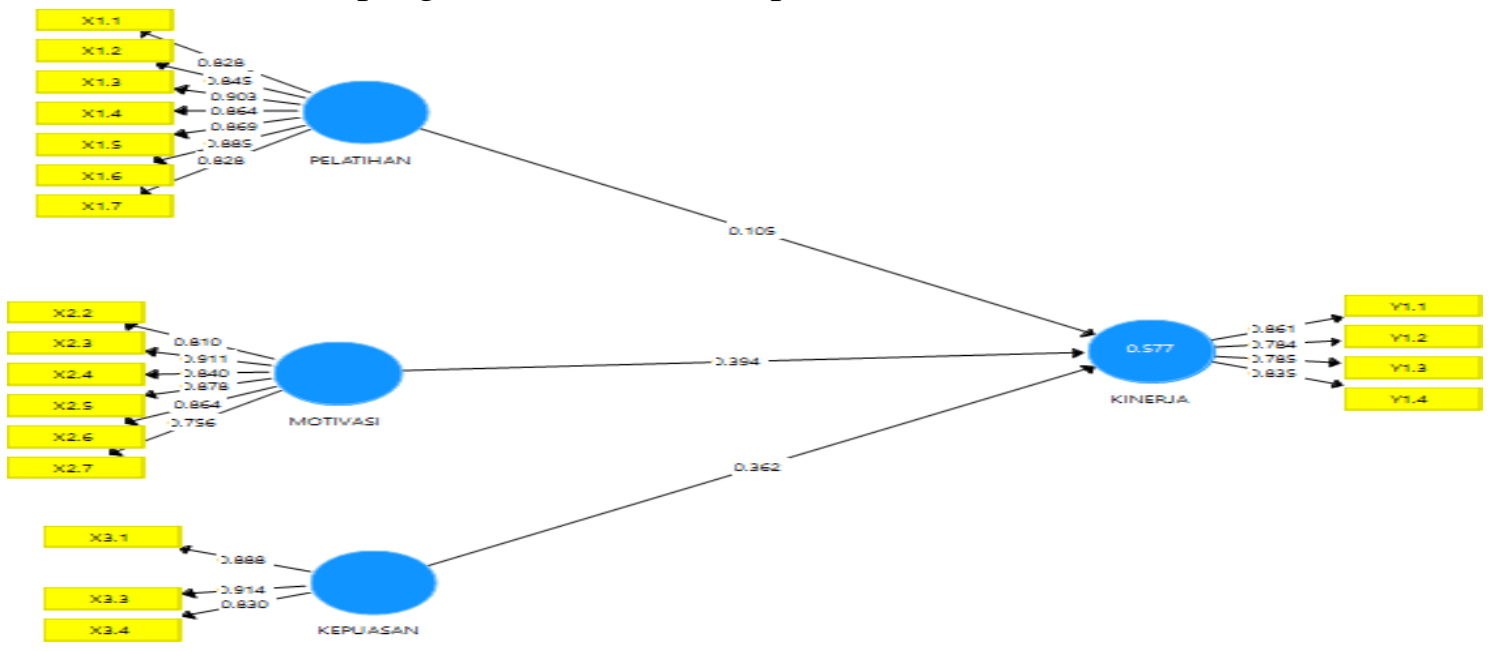

Gambar 3 Outer Loding Tahap Kedua

Sumber: data diolah, 2021 
Tabel 4 Outer Loading Tahap Kedua

\begin{tabular}{|c|c|c|c|c|}
\hline & kepuasan & kinerja & motivasi & Pelatihan \\
\hline X1.1 & & & & 0,828 \\
\hline X1.2 & & & & 0,845 \\
\hline X1.3 & & & & 0,903 \\
\hline X1.4 & & & & 0,864 \\
\hline X1.5 & & & & 0,869 \\
\hline X1.6 & & & & 0,885 \\
\hline X1.7 & & & & 0,828 \\
\hline X2.2 & & & 0,81 & \\
\hline X2.3 & & & 0,911 & \\
\hline X2.4 & & & 0,84 & \\
\hline X2.5 & & & 0,878 & \\
\hline X2.6 & & & 0,864 & \\
\hline X2.7 & & & 0,756 & \\
\hline X3.1 & 0,888 & & & \\
\hline X3.3 & 0,914 & & & \\
\hline X3.4 & 0,83 & & & \\
\hline Y1.1 & & 0,861 & & \\
\hline Y1.2 & & 0,784 & & \\
\hline Y1.3 & & 0,785 & & \\
\hline Y1.4 & & 0,835 & & \\
\hline
\end{tabular}

Berdasarkan dari pengolahan data melalui outer loading tahap dua dapat dilihat bahwa semua indicator dapat dikatakan valid setelah mengeliminasi indikator berwarna merah atau indicator yang memiliki nilai dibawah 0,7. Indikator yang terdapat dalam tabel tersebut memiliki nilai lebih dari 0,7 sehingga indicator tersebut dapat dikatakan valid

\subsubsection{Discriminant validity}

Tabel 5. Discriminant validity

\begin{tabular}{|c|c|c|c|c|}
\hline & Kepuasan & Kinerja & Motivasi & Pelatihan \\
\hline Kepuasan & 0,792 & & & \\
\hline Kinerja & 0,69 & 0,817 & & \\
\hline Motivasi & 0,713 & 0,709 & 0,806 & \\
\hline Pelatihan & 0,656 & 0,505 & 0,461 & 0,861 \\
\hline
\end{tabular}

Berdasarkan pada tabel pengolahan data diketahui nilai akar kuadrat AVE lebih dari 0,7 atau angka yang terdapat didiagonal lebih besar dari angka dari angka dalam satu kolom. $[0,792],[0,817],[0,806],[0,861]$

\subsubsection{Uji reliabilitas}

Tabel 6. rata tata AVE 


\begin{tabular}{|c|c|}
\hline & Rata-Rata Varian Diesktrak (AVE) \\
\hline Kepuasan & 0,627 \\
\hline Kinerja & 0,668 \\
\hline Motivasi & 0,649 \\
\hline Pelatihan & 0,741 \\
\hline
\end{tabular}

Tabel 7 reliabilitas komposit

\begin{tabular}{|c|c|}
\hline & Reliabilitas komposit \\
\hline kepuasan & 0,865 \\
\hline Kinerja & 0,889 \\
\hline motivasi & 0,928 \\
\hline pelatihan & 0,952 \\
\hline
\end{tabular}

Reliabilitas konstruk yang diukur dengan nilai composite reliability, konstruk reliabel jika nilai composite reliability di atas 0,70 maka indikator disebut konsisten dalam mengukur variabel latennya.

\subsubsection{Evaluasi Model Struktural (Inner Model)}

Berdasarkan dari pengolahan data maka R Square sebagai berikut

Tabel 8. R square

\begin{tabular}{|c|c|c|}
\hline & R square & Adjusted R square \\
\hline kinerja & 0,577 & 0,531 \\
\hline
\end{tabular}

R square 1 untuk kinerja karyawan (Y) sebesar 0,577 yang artinya variabel kinerja karyawan (Y) dapat diprediksi oleh dua variabel yaitu pelatihan (X1), motivasi (X2), kepuasan kerja (X3). Sehingga dapat disimpulkan bahwa $\mathrm{R}$ square memiliki pengaruh moderate antara variabel eksogen dan endogen.

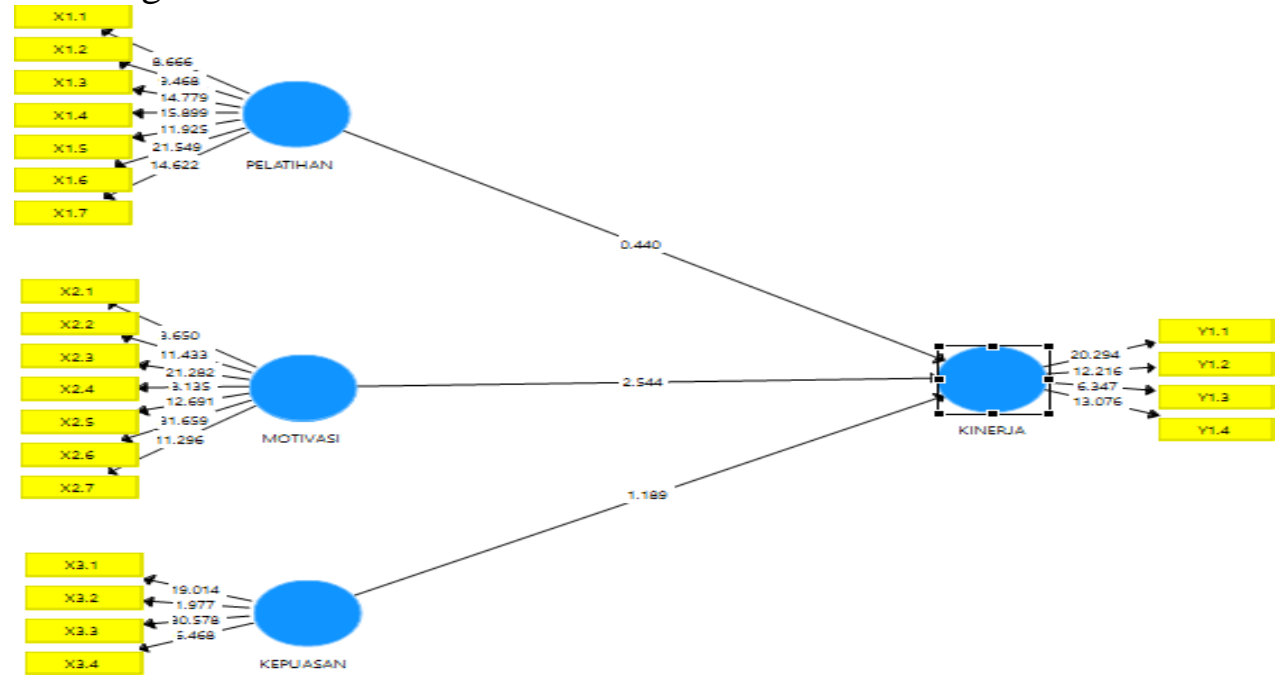

Gambar 5 outer loading

Sumber : Data Diolah, 2021

Tabel 9. $P$ Value 


\begin{tabular}{|l|l|l|l|l|c|}
\hline & $\begin{array}{c}\text { Sampel } \\
\text { Asli } \\
(\mathrm{O})\end{array}$ & $\begin{array}{c}\text { Rata- } \\
\text { Rata } \\
\text { Sampel } \\
(\mathrm{M})\end{array}$ & $\begin{array}{c}\text { Standar } \\
\text { Deviasi } \\
(\text { STDEV) }\end{array}$ & T Statistik & $\begin{array}{c}\text { P } \\
\text { Value }\end{array}$ \\
\hline $\begin{array}{l}\text { kepuasan } \\
\text { kinerja }\end{array}$ & 0,31 & 0,331 & 0,249 & 1,248 & 0,213 \\
\hline $\begin{array}{l}\text { motivasai-> } \\
\text { kinerja }\end{array}$ & 0,443 & 0,439 & 0,175 & 2,528 & 0,012 \\
\hline $\begin{array}{l}\text { pelatihan }-> \\
\text { kinerja }\end{array}$ & 0,097 & 0,091 & 0,212 & 0,455 & 0,65 \\
\hline
\end{tabular}

Berdasarkan hasil dari outer loading melalui bootstrapping dengan $\mathrm{T}$ tabel $(2,036)$. Maka $\mathrm{t}$ statistik hasil bootstrapping telah memenuhi syarat validitas. Hal ini di buktikan dengan $\mathrm{T}$ statistiknya lebih dari T table

Tabel 10. Bootstrapping

\begin{tabular}{|l|l|l|l|l|l|}
\hline & $\begin{array}{c}\text { Sampel } \\
\text { Asli } \\
(\mathrm{O})\end{array}$ & $\begin{array}{c}\text { Rata- } \\
\text { Rata } \\
\text { Sampel } \\
(\mathrm{M})\end{array}$ & $\begin{array}{c}\text { Standar } \\
\text { Deviasi } \\
(\text { STDEV) }\end{array}$ & T Statistik & $\begin{array}{c}\text { P } \\
\text { Value }\end{array}$ \\
\hline $\begin{array}{l}\text { kepuasan } \\
\text { kinerja }\end{array}$ & 0,31 & 0,331 & 0,249 & 1,248 & 0,213 \\
\hline $\begin{array}{l}\text { motivasai-> } \\
\text { kinerja }\end{array}$ & 0,443 & 0,439 & 0,175 & 2,528 & 0,012 \\
\hline $\begin{array}{l}\text { pelatihan - > } \\
\text { kinerja }\end{array}$ & 0,097 & 0,091 & 0,212 & 0,455 & 0,65 \\
\hline
\end{tabular}

Berdasarkan hasil dari koefisien jalur tabel diatas untuk pengukuran besarnya pengaruh antar variabel maka didalam penelitian ini menggunakan pebandingan $T$ tabel $(2,036)$ dengan $T$ statistik. Jika T statistic $>\mathrm{t}$ tabel maka variabel tersebut berpengaruh. Jika $\mathrm{t}$ statistic $<\mathrm{t}$ tabel.

\subsection{Pembahasan}

\subsubsection{Pelatihan tidak berpengaruh positif terhadap kinerja pegawai.}

Berdasarkan hasil dari pengelolaan data melalui outer dan inner model sebagaimana yang ditunjukan dalam tabel uji hubungan variabel antar konstruk dapat disimpulkan bahwapelatihan kerjan tidak berpengaruh terhadap kinerja karyawan. Hal ini dibukktikan $\mathrm{P}$ value $>0,05$ $(0,650)$, T Statistik $<$ T Tabel $(0,455<2,036)$.

Ditolaknya hipotesis pertama yaitu pelatihan tidak memilik pengaruh yang signifikan terhadap kinerja karyawan. Didalam perusahaan yang peneliti lakukan penelitian sebagaian besar tidak pernah melakukan pelatihan tentang perkerjaan mereka. Mereka hanya diberikan waktu training selama 2 minggu dan tidak ada pelatihan setiap bulannya.

Hal ini sejalan dengan penelitian dari (Priyanto, 2018) menyatakan bahwa pelatiahan tidak berpengaruh terhadap kinerja karyawan. Perusahaan tidak melakukan pelatihan terhadap karyawan dikarenakan para perkerja adalah pegawai Borongan (paruh waktu) dimana pegawai tersebut sudah mengetahui cara kerjanya Ketika masa training di awal masuk kerja. 


\subsubsection{Motivasi berpengaruh positif terhadap kinerja pegawai.}

Berdasarkan hasil dari pengelolaan data melalui outer dan inner model sebagaimana yang ditunjukan dalam tabel uji hubungan variabel antar konstruk dapat disimpulkan bahwamotivasi berpengaruh positif terhadap kinerja usaha. Hal ini dibukktikan $\mathrm{P}$ value $<0,05(0,012), \mathrm{T}$ Statistik > T Tabel $(2,528>2,036)$.

Di terimanya hipotesis ke dua yaitu motivasi berpengaruh sigfikasikan terhadap kinerja karyawan , karena suatu motivasi sangat di butuhkan oleh setiap manusia. Dengan pemberian motivasi dapat meningkatkan suatu tingkat produktifitas dari suatu orang serta agar meningkatkan suatu tingkat dari kinerja karyawan itu sendiri.

Hal ini juga sejalan dengan penelitian dari (Wijaya \& Susilo, 2018) yang menyatakan bahwa motivasi berpengaruh terhadap kinerja karyawan. Karyawan senang jika diberikan dorongan oleh pihak manajemen. Dorongan motivasi ini dapat menumbuhkan kinerja dalam diri karyawan.

\subsubsection{Kepuasan kerja tidak berpengaruh positif terhadap kinerja pegawai.}

Berdasarkan hasil dari pengelolaan data melalui outer dan inner model sebagaimana yang ditunjukan dalam tabel uji hubungan variabel antar konstruk dapat disimpulkan bahwa kepuasan kerja positif terhadap kinerja usaha. Hal ini dibukktikan P value $>0,05(0,213), T$ Statistik $<$ T Tabel $(1,248<2,036)$.

Ditolaknya hipotesis ke tiga yaitu kepuasan tidak memilik pengaruh yang signifikan terhadap kinerja karyawan. Didalam perusahaan yang peneliti lakukan sebagaian besar karyawan tidakmementingkan rasa akan puas dengan perkerjaan mereka. Karena mereka hanya mengetahui bagaimana cara mereka memproduksi agar sesuai target dan akan mendapatkan imbalan sesuaidengan targetnya.

Hal ini selaras dengan penelitian dari (Nur, 2018) mengatakan bahwa kepuasan tidak berpengaruh terhadap kinerja karyawan. Karyawan lebih menyukai perkerjanya yang cepat dan memenuhi target setelah itu dia akan mendapatkan upah.

\section{KESIMPULAN}

\section{Kesimpulan}

Kesimpulan dan saran dalam penelitian ini sebagaiberikut:

1) Pelatihan tidak memberikan pengaruh yang baik dalam peningkatan kinerja. Kebanyakan karyawan di UD Rohman berkerja dengan otodidak atau berkerja langsung. Karyawan yang baru diberikan pelatihan dengan training selama 2 minggu.

2) Motivasi memberikan pengaruh yang sangat baik dalam peningkatan kinerja. Karyawaan lebih suka mendengarkan motivasi yang diberikan dari owner atau pihak supervisor.

3) Kepuasan kerja tidak memberikan pengaruh dalam peningkatan kinerja. Karyawan tidak memiliki kepuasan dalam berkerja. Ada sebagaian karyawan yang berkerja tidak sesuai harapan terkadang sering mendapatkan teguran dari pihak supervisor.

\section{Saran}

Berdasarkan penelitian ini, ada beberapan saran yang diharapkan menjadi masukan bagi perusahaan. Adapun saran tersebut yaitu antara lain:

1) Di harapkan perusahaan dapat meningkatkan jumlah insentitas pelatihan terhadap para karyawan yang ada hal ini bertujuan untuk meningkatkan performa yang di miliki para 
karyawan dan juga untuk meningkatkan jumlah produksifitas dari prodak itu sendiri

2) Di harapkan perusahaan dapat meningkatkan tingkat motivasi dari para karyawan agar karyawan semakin terdorong dan tertantang dalam melakukan pekerjaannya setiap hari Dan serta untuk meningkatkan kepuasan kerja dan kinerja dari karyawan itu sendiri.

3) Disaran untuk peneliti selanjutnya agar mengembangkan penelitian ini dengan mengcustom dan memodifikasi variabel supaya menarik diteliti kembali dan memperluas wilayah penelitian.

\section{DAFTAR PUSTAKA}

Jogiyanto, H., \& Abdillah, W. (2015). Partial least square (PLS) : alternatif structural equation modeling (SEM) dalam penelitian bisnis. Yogyakarta: Andi Offset.

Marjaya, I., \& Pasaribu, F. (2019). Pengaruh Kepemimpinan, Motivasi, Dan Pelatihan Terhadap Kinerja Pegawai. Maneggio: Jurnal Ilmiah Magister Manajemen, 2(1), 129_ 147.

Ningsi, C. A., Alhabsji, T., \& Utami, H. N. (2016). Pengaruh Pelatihan Dan Promosi Terhadap Motivasi Dan Kinerja Karyawan (Studi Pada Karyawan Pt. pln (Persero) Area Kendari). Jurnal Ilmiah Ilmu Administrasi Publik, 5(2), 131-143.

Nugroho, M. N., \& Paradifa, R. (2020). PENGARUH PELATIHAN, MOTIVASI, KOMPETENSI TERHADAP KINERJA SUMBER DAYA MANUSIA. JRMSI-Jurnal Riset Manajemen Sains Indonesia, 11(1), 149-168.

Nur, A. (2018). Pengaruh Kepuasan, Motivasi Dan Kedisiplinan Kinerja Terhadap Kinerja Pegawai Di Lingkungan Kantor Wilayah Departemen Agama Provinsi Jawa Tengah.

Poole, L. (2013). Perfect Phrases for Coaching Employee Performance: Hundreds of Ready-touse Phrases for Building Employee Engagement and Creating Star Performers. McGrawHill Education.

Priyanto, F. A. (2018). Pengaruh kompensasi finansial dan nonfinansial, pemanfaatan teknologi informasi dan budaya organisasi terhadap kinerja karyawan (Studi Empiris di PT Pos Indonesia (Persero) Cabang Pangkalpinang). Universitas Bangka Belitung.

Sataloff, R. T., Johns, M. M., \& Kost, K. M. (2003). 主観的健康感を中心とした在宅高齢者における健康関連指標に関する共分散構造 分析 (特集 人々の健康を支援する方法). 総合都市研究, 81, 19-30.

Setia, A., Marnis, M., \& Garnasih, R. L. (2020). ANALISIS PENGARUH PELATIHAN, KEPUASAN KERJA, DAN TEAMWORK TERHADAP KINERJA KARYAWAN DENGAN KEPEMIMPINAN SEBAGAI VARIABEL MODERASI PADA PT. PERKEBUNAN NUSANTARA V (PTPN V) DI PEKANBARU. Procuratio: Jurnal Ilmiah Manajemen, 8(2), 202-215.

SIAGIAN, M. (2020). PENGARUH DISIPLIN DAN MOTIVASI KERJA TERHADAP KINERJA KARYAWAN PT. MITRA HOSINDO SEJAHTERA. JURNAL ILMIAH KOHESI, 4(3), 181-188.

Sugiyono. (2014). Quanitative Research Method, Qualitative and Combined (Mix Methods). Bandung: Alfabeta, 53.

Sunyoto, D. (2013). Manajemen Sumber Daya Manusia. Yogyakarta: CAPS (Center Of Academic Publishing Service).

Susila, G. P. A. J., Suarmanayasa, I. N., \& Parma, P. G. (2019). The Effect of Training and Work Motivation on Employee Performance. International Conference on Education, 
Raynaldy Rizky R., Mei Retno Adiwati / Edunomika Vol. 05, No. 02 (2021)

Social Sciences and Humanities, 83-85.

Wijaya, A. J., \& Susilo, H. (2018). PENGARUH MOTIVASI TERHADAP KINERJA (Studi Pada Karyawan PT. Ika Jaya Sahara Karya Malang). Jurnal Administrasi Bisnis, 60(1), 180-186. 